\title{
A Miracle Obstetrical Result: Iso-immunized Baby with HighTiter with Good Foetal Outcome
}

\author{
RC LK \\ Department of Obstetrics and Gynaecology, Patan Academy of Health Sciences, Lalitpur, Nepal.
}

Received: December 05, 2014; Accepted: March 12, 2015

\begin{abstract}
We present a case of 26 years multigravid women $\left(\mathrm{G}_{2} \mathrm{P}_{0} \mathrm{~A}_{1}\right)$ with iso-immunized foetus with high titre 1:512, delivered at $36^{+6}$ weeks of pregnancy. She visited the hospital in the second trimester of pregnancy for routine antenatal check up. There was a past history of spontaneous abortion at 12 weeks where no immunoglobulin (rhogam) injection was taken. At $22^{+}$weeks of gestation, she was admitted in the hospital with titre 1:128 and 1:512. Counseling was done for outcome of foetus and advised for termination, but parents wanted to continue the pregnancy. Dexamethasone injection was given for foetal lung maturity and then discharged. Baby was kept in the nursery and double phototherapy was given and discharged at the seventh day of life.
\end{abstract}

Keywords: abo- incompatibility; rhesus incompatibility; rhesus isoimmunization, rhesus negative.

\section{INTRODUCTION}

Isoimmunization has been defined as the process whereby antibodies are produced in an individual in response to the injection of antigen from another individual of the same species, which the recipient lacks. ${ }^{1}$

Rhincompatibility can occur by two main mechanisms. The most common type occurs when an Rh-negative pregnant mother is exposed to Rh-positive foetal red blood cells secondary to foetomaternal haemorrhage during the course of pregnancy from spontaneous or induced abortion and trauma. ${ }^{2}$

A recent review of the 2001 birth certificates in the US by the Centers for Disease Control and Prevention indicates that Rh sensitization still affects 6.7 out of every 1,000 live births. ${ }^{3}$

Before the introduction of anti-D immune globulin (formerly referred to as Rho[D] immune globulin), haemolytic disease of the foetus and newborn affected $9-10 \%$ of the pregnancies and was a major cause of perinatal morbidity and mortality. Most

\section{CORRESPONDENCE}

Dr Laxmi RC

Department of Obstetrics and Gynaecology, Patan Academy of Health Sciences, Lalitpur, Nepal.

Email:dr_lax50@hotmail.com

Phone:+977-9851085326 women who become isoimmunized do so as a result of foetomaternal haemorrhage of less than $0.1 \mathrm{~mL}$. Several first- and second-trimester clinical events may cause Rh D isoimmunization. Therapeutic and spontaneous abortions are associated respectively with a $4-5 \%$ and a $1.5-2 \%$ risk of isoimmunization in susceptible (non-isoimmunized) women. Ectopic pregnancy also is associated with isoimmunization in susceptible women. Threatened abortion infrequently causes isoimmunization, clinical procedures, which may breach the integrity of choriodecidual space, also may cause $\mathrm{Rh} \mathrm{D}$ isoimmunization. Chorionic villus sampling is associated with a $14 \%$ risk of foetomaternal haemorrhage, even if the placenta is not traversed. Likewise, cordocentesis and other percutaneous foetal procedures pose a risk for foetomaternal haemorrhage. External cephalic version, whether or not it is successful, results in foetomaternal haemorrhage in $2-6 \%$ of the cases. ${ }^{4}$

The Rhesus blood type was first discovered in 1937 by Karl Landsteiner and Alexander S. Wiener. ${ }^{5}$

Haemolytic disease of the newborn, secondary to rhesus isoimmunisation was once a major contributor to perinatal morbidity and mortality. Today, rhesus immune globulin has markedly decreased the prevalence of this disease so much that less than three cases occur in every 1000 live births. ${ }^{6}$ 
The rarity of this condition warrants referral to a maternal-foetal medicine specialist. Once sensitization occurs, rhesus immune globulin is no longer effective. Maternal antibody titres cannot be used for screening foetal anaemia. Conventionally, serial amniocenteses were performed for spectrophotometric studies to detect foetal bilirubin for estimating foetal anaemia, based on the Liley's reference chart. Serial peak middle cerebral artery velocities using doppler ultrasound have now become the mainstay of screening for foetal anaemia. ${ }^{7}$

It is possible to encounter women with titers as high as 512 with foetuses that are negative for the antigen to which the antibody is directed. ${ }^{8}$

\section{CASE}

A 26 years multigravid patient $\left(\mathrm{G}_{2} \mathrm{P}_{0} \mathrm{~L}_{0} \mathrm{~A}_{1}\right)$ first visited in outpatient department for antenatal checkup at 18 weeks of pregnancy (by scan) with blood group $\mathrm{B}$-ve and husband $\mathrm{O}+\mathrm{ve}$ with past history of one miscarriage where no immunoglobulin was taken. She had irregular cycle. Routine investigation was sent where indirect coomb's test was 1:128. Other investigation was within normal limit. With high titre, the husband and wife was couselled about foetal prognosis and for termination but both partners refused admission and termination. They wanted to continue the pregnancy. At 22 weeks of pregnancy, she came with indirect coomb's titre 1:512. In this stage, she was admitted and given two doses (six milligram 12 hourly four doses) of dexamethasone injection, counselling to the couple was contineus for prognosis of the baby but they wanted continuation of pregnancy. At 34 weeks of pregnancy, she was advised for delivery but refused. Ultrasonography was done every two weeks which showed normal foetus till this stage. At 36 weeks of pregnancy, she was presented at labour room with labour pain and delivered vaginally a male baby with apgar score 7/10-9/10 and weighing 2,650 gram.

Baby was transferred to the nursery. Baby's blood group was $\mathrm{O}+\mathrm{ve}$, direct coomb's test was negative with high level of bilirubin, received multiple episodes of double and single photo therapy and discharged on the seventh days of life. Table 1 shows the result of indirect coomb's test at different weeks of gestation.

\begin{tabular}{|ll|}
\hline $\begin{array}{l}\text { Table 1. Weeks of pregnancy and result of indirect } \\
\text { coomb's test. }\end{array}$ \\
\hline Weeks of gestation & Result of indirect \\
& coomb's test \\
18 & $1: 128$ \\
22 & $1: 128$ \\
26 & $1: 512$ \\
30 & $1: 512$ \\
32 & $1: 512$ \\
34 & $1: 512$ \\
\hline
\end{tabular}

Baby was admitted twice in the pediatric department with diagnosis of pneumonia and diarrhoea at the age of four months and six months of life. Later three episodes at four moths ans six months of life for follow up visited in outpatient department for upper respiratory tract infection and treated with anibiotics.

Now baby is two years old and he is healthy.

\section{COMMENT}

Isoimmunised pregnancies are at an increased risk of developing foetal anaemia, hydrops and stillbirth. Pregnancies at risk for haemolytic disease conventionally underwent serial amniocentesis for spectrophotometric measurement of bilirubin as an evidence of foetal haemolysis and anaemia. ${ }^{9}$ But our baby was normal in serial ultasonography and direct coomb's test was also negative with high titre (1:512) for indirect coomb's.

To minimise invasive procedures and determine the optimal timing of intervention, a number of studies were performed to evaluate reliability and usefulness of noninvasive parameters. ${ }^{10}$

Our baby also had high level of bilirubin but there was no exchange transfusion but he received multiple episode of phototheraphy.

In summary, the aim of this article is to inform obstetricians and gynaecologists through this evidential case report that isoimmunised baby with high titre (1:512) could have good foetal outcome and not necessarily need termination every time. 


\section{DISCLOSURE}

The authors report no conflicts of interest in this work

No violation of human rights and safety.

Funding: Nil

\section{REFERENCES}

1. Mishra R. Rhesus isoimmunisation. In: Kriplani A, Malhotra B, Nayar B, editors. A Donald's Practical Obstetric Problems. $6^{\text {th }}$ ed. India: Edward Arnold; 2007. p. 377.

2. Thorp JM. Utilization of anti-RhD in the emergency department after blunt trauma. Obstet Gynecol Surv 2008;63(2):112-5

3. Martin JA, Hamilton BE, Ventura SJ. Births: final data for 2001. Natl Vital Stat. 2002;51:1-104.

4. Serrano MA, Bayon JE, Pascolo L. Evidence for carrier mediated transport of unconjugated bilirubin across plasma membrane vesicles from human plancental trophoblast. Journal of Hepatology. 2002;23:527-535.
5. Landsteiner K, Weiner AS. An agglutinable factor in human blood recognized by immune sera for rhesus blood. Exp Bio Med. 1940; 43(1):223-4.

6. Mclean LK, Hedriana HL, Lanouette JM, Hanns C, Haesslein. A retrospective review of isoimmunised pregnancies managed by middle cerebral artery peak systolic velocity. AJOG. 2004;190:1732-8

7. Detti L, Mari G, Akiyama M, Cosmi E, Moise KJ, Stefor et al. Longitudinal assessment of the middle cerebral artery peak systolic velocity in healthy foetuses and in foetuses at risk for anemia. AJOG. 2002;937-9.

8. Copel JA, Scioscia A, Grannum PA, Romero R, Reece EA, Hobbins JC. Related articles percutaneous umbilical blood sampling in the management of Kell isoimmunization. Obstet Gynecol. 1986;67(2):288-90.

9. Mari G. The collaborative group for diagnosis of foetal anaemia with doppler ultrasonography. Noninvasive diagnosis by doppler ultrasonograph of foetal anemia due to maternal red cell alloimmunisation. N Engl J Med. 2000;342:9-14.

10. Divakaran TG, Waugh J, Clark TJ, Khan KS, Whittle MF, Kilby MD. Noninvasive techniques to detect foetal anaemia because of red blood cell alloimmunisation: A systematic review. Obstet Gynecol. 2001;98:509-17. 